\title{
Correction to: Viscosities of Liquid Refrigerants from a Rough Hard-Sphere Theory-Based Semi-Empirical Model
}

\author{
F. Yousefi ${ }^{1} \cdot$ S. M. Hosseini ${ }^{2} \cdot$ K. Hamidi $^{1} \cdot$ M. Pierantozzi ${ }^{3}$
}

Published online: 21 January 2022

(c) Springer Science+Business Media, LLC, part of Springer Nature 2022

\section{Correction to: International Journal of Thermophysics (2019) 40:74 https://doi.org/10.1007/s10765-019-2541-1}

In this article, Eq. (6) contained an error in the universal function of reduced temperature $\left(T^{*}\right)$. The corrected Equation is given below,

$$
F_{s}=0.2438\left(T^{*}\right)^{2}+0.0661\left(T^{*}\right)-0.0086
$$

Publisher's Note Springer Nature remains neutral with regard to jurisdictional claims in published maps and institutional affiliations.

The original article can be found online at https://doi.org/10.1007/s10765-019-2541-1.

\section{F. Yousefi}

fyousefi@mail.yu.ac.ir

$\triangle$ S. M. Hosseini

sm.hosseini@hormozgan.ac.ir

1 Department of Chemistry, Yasouj University, 75914-353 Yasouj, Iran

2 Departments of Chemistry, Faculty of Sciences, University of Hormozgan, Bandar Abbas 71961, Iran

3 SAAD, Università degli Studi di Camerino, 63100 Ascoli Piceno, Italy 